\title{
Notas preliminares sobre el sitio arqueológico San Salvador, Bajo Ucayali - Perú
}

\author{
Jorge Carranza Orbegoso
}

j.carranzaorbegoso@gmail.com

Universidad Nacional Federico Villarreal

\section{RESUMEN:}

La presente nota de investigación expone algunas observaciones acerca del sitio arqueológico San Salvador y una muestra de material cerámico y lítico proveniente del mismo, dentro del contexto arqueológico del bajo Ucayali.

De modo preliminar, se define el sitio arqueológico como un asentamiento con área de cementerio de entierros secundarios colocados en urnas funerarias. El análisis inmediato de los elementos indicados sitúa temporalmente al sitio arqueológico al interior de los periodos prehispánicos tardíos de la llanura amazónica. Palabras Clave: Urnas funerarias; Cementerio; San Salvador; Contamana; Bajo Ucayali.

\section{Preliminary Notes on the Archaeological site of San Salvador, Lower Ucayali River Valley, Perú}

\begin{abstract}
:
This research discusses some observations about the archaeological site of San Salvador, in the lower Ucayali River Valley, based on ceramics and lithic materials recovered in may of 2016. The archaeological site is preliminarily defined as a domestic settlement with a cemetery area showing secondary burials placed in urns. Immediate analysis of the indicated evidences assign thi site in the late pre-hispanic periods of the cultural sequence.
\end{abstract}

Keywords: Funeral urns; Cemetery; San Salvador; Contamana; Bajo Ucayali. 
«Excavando la tierra encontramos miles de cerámicas rotas», dicen los Shipibo, "pero no los tocamos porque están encantadas. Los colonos quechua hablantes llaman al lugar de bajada Canchahuaya, dado que no pueden pronunciar nuestro idioma. Nosotros lo llamamos Quenchaya Manán, el cerro de las vasijas de cerámica».

(Heath, 2002, p. 26)

\section{Introducción}

En mayo de 2016 desarrollamos una visita al centro poblado San Salvador, donde tuvimos la oportunidad de reconocer la zona que ocupa esta localidad.Durante nuestra permanencia, inspeccionamos el área del sitio arqueológico San Salvador y registramos las evidencias en superficie, al igual que el material recuperado y custodiado en la Institución Educativa Primaria (IEP) N. 64204 San Salvador. En favor de brindar mayor información sobre el sitio arqueológico desarrollamos la presente nota, la cual esperamos sirva de incentivo para futuras investigaciones en el lugar.

\section{Ubicación y marco geográfico}

San Salvador es el nombre de un centro poblado rural ubicado en la ribera oeste de la laguna Maquía, margen derecha del río Ucayali, en la llanura amazónica. Se localiza a unos $5.5 \mathrm{~km}$ del centro urbano del distrito de Contamana, provincia de Ucayali, en la región Loreto. Esta zona se caracteriza por presentar campos de cultivo y grandes extensiones de pastizales dedicados a la crianza de ganado vacuno (Shapiama, 2013) (Figura 1-2).

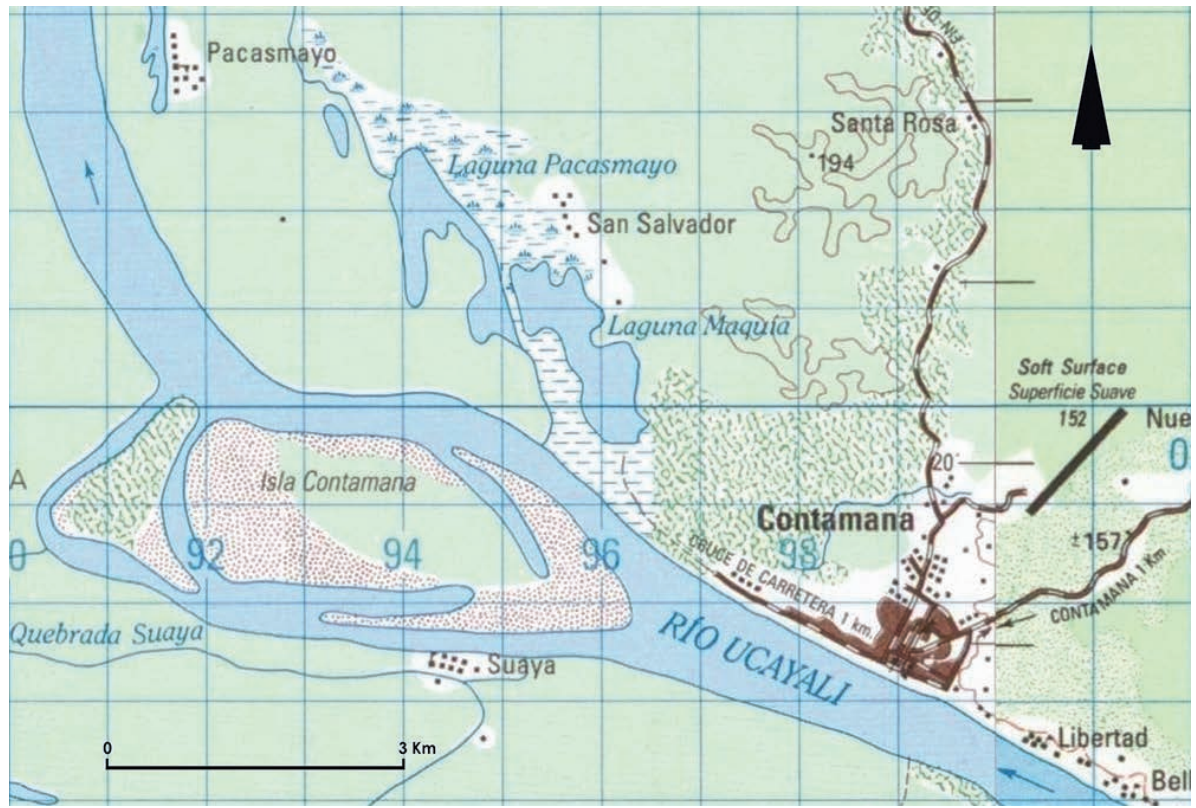

Figura 1. Centro poblado rural San Salvador (Contamana-Ucayali-Loreto). Composición basada en la Carta Nacional del Perú (Hoja 15m Contamana y Hoja 15n Puerto Oriente), escala 1:100,000; impresa en 1998, del Instituto Geográfico Nacional. 


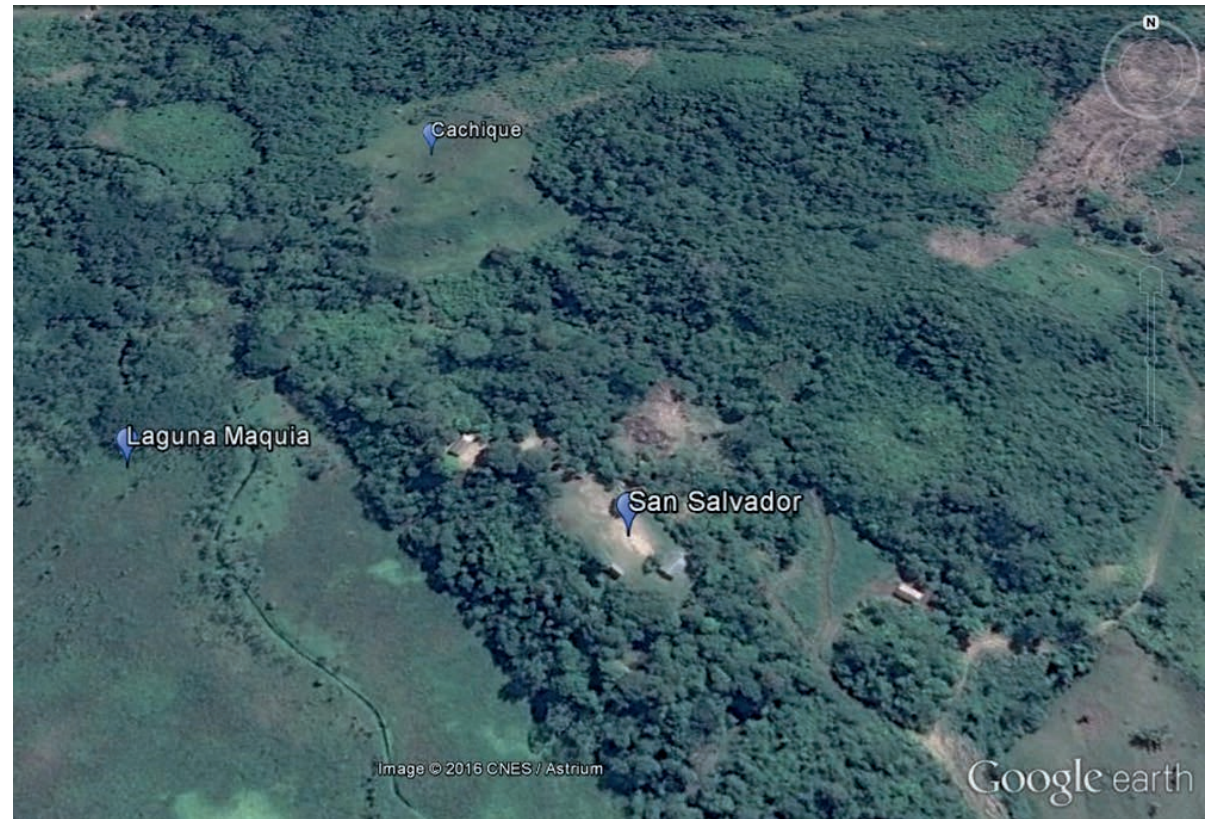

Figura 2. Perspectiva norte del sitio arqueológico San Salvador con referencia al sector Cachique y la laguna Maquía. Fuente: Google Earth, Image C2016 CNES/ Astrium, 25 de julio del 2013, elevación 150 m.

El área donde se encuentra asentado el poblado presenta un relieve de suave ondulación, en el que sobresalen colinas de baja elevación cubiertas de vegetación boscosa. Al este resaltan los cerros del Parque Nacional Cordillera Azul y al oeste la Serranía de Contamana, o cerro Canchahuaya, actualmente componente del Parque Nacional Sierra del Divisor.

El acceso al centro poblado se realiza, desde la urbe, por vía terrestre siguiendo la trocha carrozable Contamana-San Salvador y por vía fluvial continuando por el río Ucayali, aguas abajo, ingresando a la laguna Maquía en dirección al caserío.

\section{Investigaciones previas}

A fines de la década del cincuenta, Blissenbach(1992) registra una serie de evidencias arqueológicas aisladas, durante la habilitación de accesos y áreas para la perforación de pozos exploratorios en el campo petrolero de Maquía y el área de los pozos de exploración Inuya y Cashiboya, consistentes en fragmentos de cerámica decorada (incisa y pintada), hachas pulimentadas y material óseo. Basado en estos hallazgos, plantea la existencia de sitios arqueológicos y señala la presencia de urnas funerarias, sugiriendo la filiación del material recolectado a la tradición cultural Cumancaya.

En los últimos años, residentes del centro poblado rural Betania, próximo al campo petrolero de Maquía, han reportado el hallazgo de urnas funerarias en el área del caserío (Impetu, 2012, p. 4).

Durante la década de 1960, Lathrap y sus estudiantes desarrollaron un programa de investigación arqueológica en la cuenca media del río Ucayali, el cual estuvo orientado a esclarecer la historia cultural prehispánica del Alto Amazonas (Lathrap, 1965; Rivas ed., 2010). Como parte de dicho programa, en 1964, Myers (1967) realizó exploraciones arqueológicas en el bajo Ucayali, ubicando sitios arqueológicos en Orellana (UCA 26, UCA 27), laguna Piracocha - José Olaya (UCA 28, UCA 29, UCA 30) y Contamana (UCA 31), los cuales están relacionados a los complejos arqueológicos de Ohanana, Olaya y Cumancaya. Adicionalmente realizó investigaciones arqueológicas en la antigua Misión Franciscana de Sarayacu (SAR 1) 
y Santa María de Belén (SAR 2), sitios de carácter histórico (Myers, 1990). En la actualidad, los pobladores de Orellana han reportado el hallazgo de áreas con material arqueológico en las inmediaciones del pueblo (Ahora, 2011, p. 6; El Contamanino [EC], 2013, p. 18).

En la segunda mitad de la década de 1980, Panaifo y Gyulavari desarrollan una serie de reconocimientos arqueológicos en el Bajo Ucayali y sus principales afluentes, localizando evidencias aisladas y sitios arqueológicos, entre los cuales destacan las Ruinas de Pauya en el río homónimo, afluente principal del río Cushabatay y el cementerio de urnas funerarias de San Salvador, en las proximidades de Contamana (Panaifo, 1994; Zevallos, 2001; Zevallos, 2015, pp. 81-85).

En el año 1988, Panaifo realizó excavaciones arqueológicas en el centro poblado San Salvador, ubicando un cementerio en el cual se hallaron entierros secundarios colocados en urnas de cerámica, de diversos tamaños y características, variando entre llanas, carenadas, cilíndricas y pintadas, presentando algunas de estas platos de cerámica, a manera de tapa. Señala que el contenido de las urnas estaba asociado a cuentas de hueso y concha, instrumentos de cobre, torteros, pequeños fragmentos de toba volcánica y fragmentos de cerámica decorada (incisa y pintada). Aunque en líneas generales, el material cultural estaría asociado a la tradición cultural Pacacocha, Cashibocaño y Cumancaya; advierte también el hallazgo de un pequeño plato con decoración incisa que lo vincula a la tradición cultural Shakimu.

Por los hallazgos fortuitos de los pobladores en los alrededores del cementerio prehispánico, Panaifo define el sitio arqueológico de San Salvador como un asentamiento habitacional con cementerio (Panaifo, 1994, pp. 187, 191).

En 1989, Gyulavari localizó un sitio arqueológico con restos arquitectónicos en el río Pauya, afluente principal del río Cushabatay, el cual fluye al interior del actual Parque Nacional Cordillera Azul. El sitio arqueológico presenta estructuras en un área aproximada de $400 \mathrm{~m}^{2}$, al parecer se trataría de edificios, construidos en mampostería simple de lajas de piedra unidas con argamasa de barro. En una segunda incursión en el año 1996, Panaifo realizó trabajos arqueológicos preliminares en el área, encontrando cerámica y artefactos líticos que asocian la arquitectura descrita con los periodos tardíos, por lo que el sitio arqueológico podría ser un enclave procedente de las culturas de la ceja de selva (Panaifo, 1994, p. 179; Selva, 1976, 1981; Zevallos, 2015, pp. 81-85).

En relación a lo expuesto, son conocidas diferentes rutas naturales que conectan el bajo Ucayali y el bajo Huallaga, entre estas tenemos los varaderos del río Santa Catalina y del Alto Cushabatay (Zevallos, 2015). En referencia al río Santa Catalina, Rivas (2006, p. 80) reporta el sitio arqueológico Cantagallo, filiándolo a la tradición Policroma.

En el marco del «Proyecto de Investigaciones de la Amazonia Peruana», Morales $(2002,2008)$ localiza sitios arqueológicos en la cuenca del río Samiria, afluente del bajo Ucayali, realizando estudios en el sitio arqueológico El Zapotal, en la ribera de la laguna Yarina, actual Reserva Nacional Pacaya Samiria. Morales (2008) señala que el sitio arqueológico El Zapotal sería un asentamiento con presencia de área doméstica y cementerio de entierros secundarios en urnas funerarias de cerámica, con estilos vinculados a la tradición cultural Policroma y Cumancaya.

En el bajo y medio Samiria, en las localidades de San José de Samiria (Morales, 2002, p. 53) y San Martín de Samiria (Forero, 2010) se han registrado sitios arqueológicos de similar importancia. En el límite norte de la Reserva Nacional Pacaya Samiria, río Marañón, próximo al 
centro poblado menor San José de Saramuro se han reportado urnas funerarias semejantes a las estudiadas en el río Samiria (ECSA Ingenieros S.A., 2008, pp. 318-331).

Por otra parte, el componente arqueológico del «Estudio de Impacto Ambiental» para los lotes de hidrocarburos 134 y 158, ubicados en la provincia de Requena, región Loreto; documentó seis áreas con hallazgos arqueológicos en las actuales locaciones de centros poblados pertenecientes a la cuenca del río Ucayali y la subcuenca del río Buncuya. En la sección que corresponde al río Ucayali se localizaron los sitios arqueológicos de Miguel Grau, Santa Teresa y Cruz Molluna; en el río Buncuya se ubicaron los sitios arqueológicos Víctor Raúl, Mállame y Buncuya. En general, las evidencias arqueológicas consisten en fragmentos de cerámica, vasijas fragmentadas y un hacha pulimentada. Destacando además la presencia de cuentas, restos óseos y una urna funeraria decorada en el poblado Cruz Molluna. Todo este material arqueológico, asociado a los periodos tardíos, fue hallado en superficie y en áreas ribereñas (Walsh Perú S.A., 2010, pp. 4.41-4.4-16).

En años recientes, Ravines (2011, pp. 376, 457) describe el sitio arqueológico San Salvador, como un asentamiento habitacional con entierros en urnas funerarias con decoración corrugada, emplazado sobre un conjunto de promontorios.

Finalmente, como parte de sus funciones, el Ministerio de Cultura ha realizado trabajos de inspección y delimitación del sitio arqueológico San Salvador, para su declaratoria e inscripción como Patrimonio Cultural de la Nación (Instituto Nacional de Cultura, 1993; Ministerio de Cultura, 2011a, 2011b). En el año 2011, Rivas desarrolló un reconocimiento al sitio arqueológico San Salvador y sus alrededores, determinando la existencia de un nuevo sitio arqueológico denominado Cachique (Agencia de Noticias de Contamana [ANC], 2011; EC, 2013, p. 18).

\section{El Sitio Arqueológico San Salvador}

El sitio arqueológico San Salvador se localiza sobre una terraza natural con cobertura boscosa, ubicada al oeste del lago Maquía, teniendo como referencia el punto de coordenadas central UTM (WGS 84): 9191883N, 495677E y una altura de 158 msnm (Figura 3).

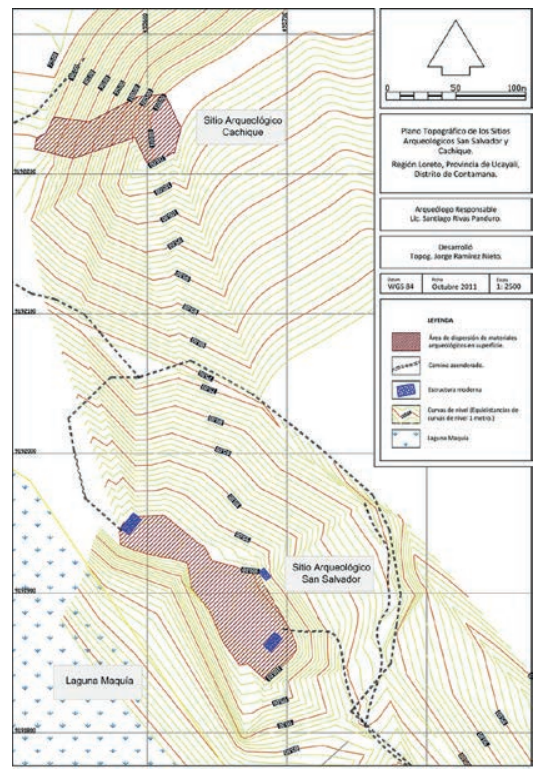

Figura 3. Plano topográfico de los sitios arqueológicos San Salvador y Cachique. Archivo Santiago Rivas Panduro, Inspección a los sitios arqueológicos San Salvador y Cachique, octubre del 2011, Iquitos. 
En el área nuclear del sitio arqueológico (eje noreste - suroeste de $160 \mathrm{~m}$ de longitud y una franja de $60 \mathrm{~m}$ de ancho) se encuentra una vivienda y la IEP N. 64204 San Salvador. La habilitación de esta infraestructura ha generado el desbroce del área, exponiendo evidencias arqueológicas en superficie, consistente en vasijas de cerámica enterrada y fragmentería asociada (Figura. 4-5).

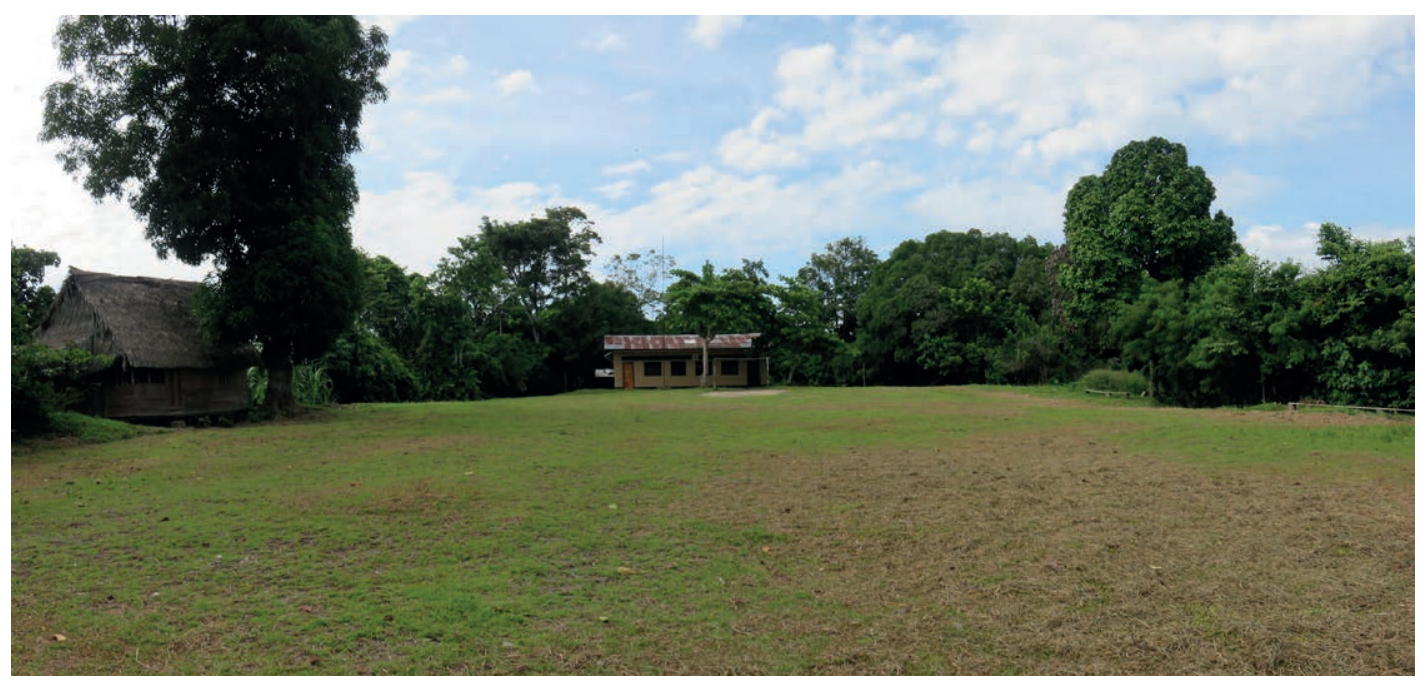

Figura 4. Vista panorámica con orientación sureste del área de la IEP Nº 64204 San Salvador.

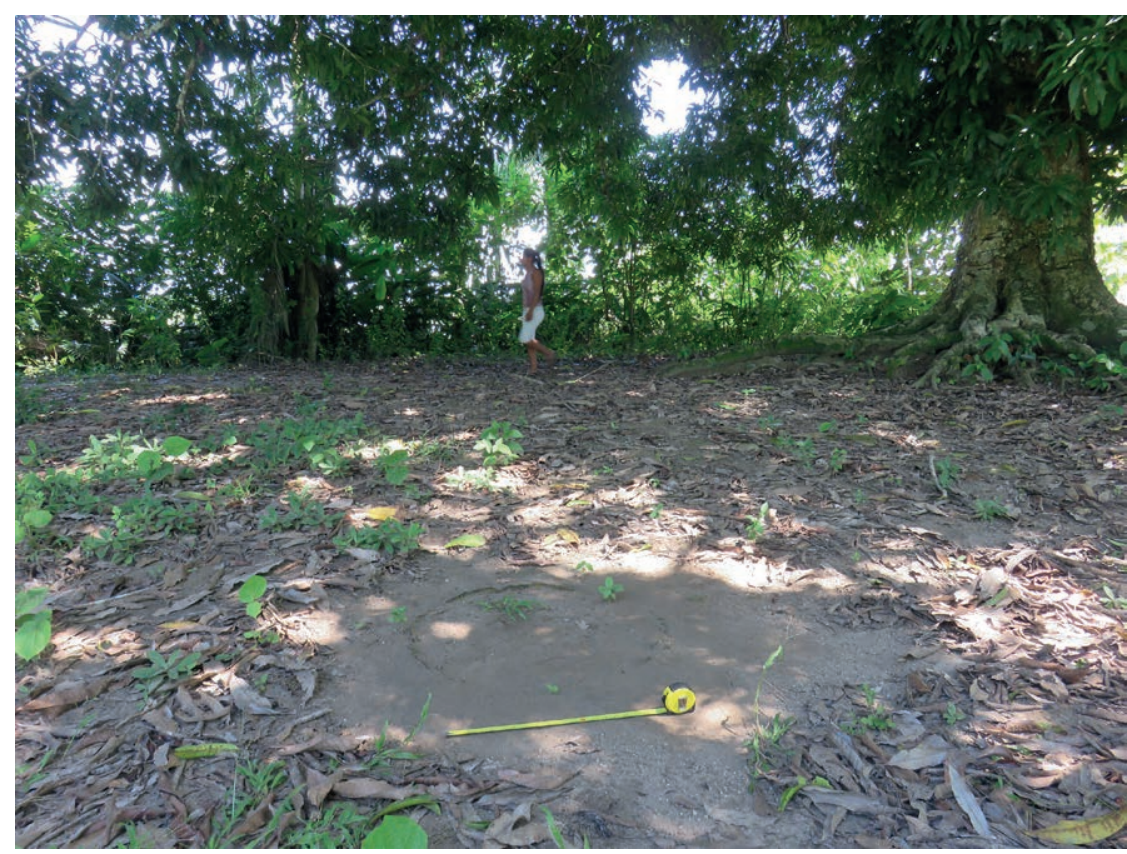

Figura 5. Borde de vasija aflorando en superficie (El flexómetro indica $50 \mathrm{~cm}$ ).

Debido a la cobertura vegetal existente en el área es impreciso establecer la extensión total del sitio arqueológico; sin embargo, consideramos que la ocupación arqueológica se extiende sobre algunos promontorios naturales vecinos. Tal es el caso del sector denominado sitio arqueológico Cachique, coordenadas de referencia UTM (WGS 84): 9192227N, 495566E, 110 msnm; ubicado próximo a la quebrada del mismo nombre (ANC, 2011) (Figura. 3 y 10). 


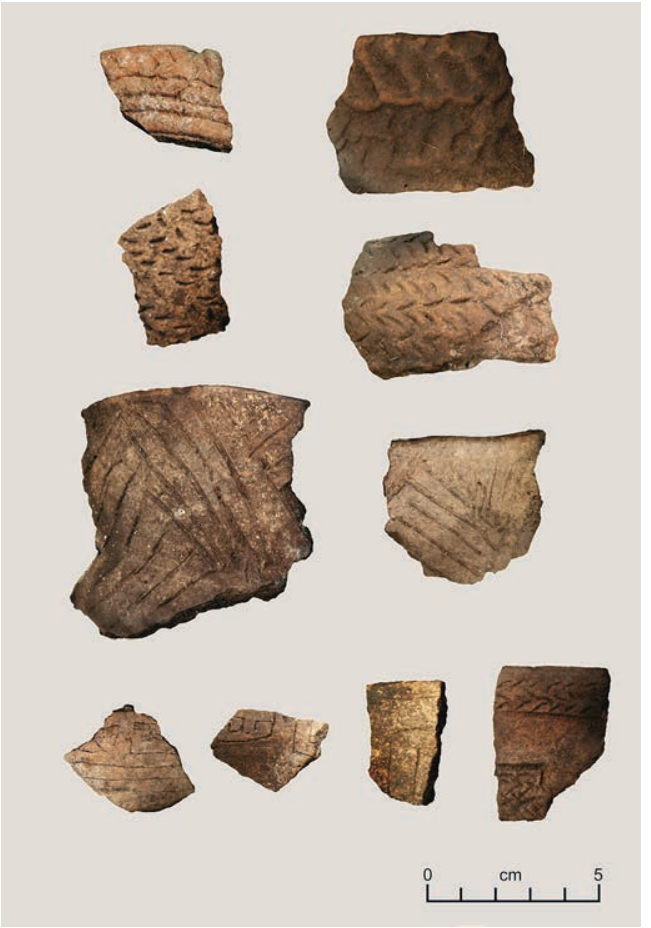

Figura 10. Fragmentos de cerámica diagnostica provenientes del sector Cachique. Archivo Santiago Rivas Panduro, Inspección a los sitios arqueológicos San Salvador y Cachique, octubre del 2011, Iquitos.

Mientras nos trasladábamos al sitio arqueológico, por la trocha carrozable Contamana - San Salvador, registramos material arqueológico (fragmentos de cerámica y material óseo) disperso en la vía, a lo largo de una longitud de $167 \mathrm{~m}$, producto del corte del terreno realizado por maquinaria pesada para la nivelación de la misma. Los puntos de coordenadas que limitan la extensión cerámica son los siguientes: Norte UTM (WGS 84): 9190477N, 496872E, 126 msnm; Sur UTM (WGS 84): 9190341N, 496970E, 142 msnm.

\section{Materiales arqueológicos}

Durante nuestra visita a la IEP N. ${ }^{\circ} 64204$ San Salvador, observamos la colección de materiales arqueológicos que guarda, la cual procede de hallazgos fortuitos realizados por los pobladores producto de sus labores agrícolas, así como de la exposición de entierros por lluvias intensas.

Entre los materiales destacan fragmentos de cerámica decorada, vasijas completas y fragmentadas, instrumentos para hilar y manos de moler (Figuras 6-7-8). También se registró material lítico pulimentado, específicamente dos hachas, una de ellas fragmentada, y dos preformas (Figura 9). En menor cantidad se observaron restos óseos humanos, entre los que resaltan un cráneo incompleto (aparentemente sin deformación) y huesos largos y planos.

Seguidamente reseñamos algunas anotaciones sobre la muestra cerámica y lítica observada en el lugar.

\section{a) Cerámica}

Fragmentos de cerámica diagnóstica: La muestra consta de más de 50 fragmentos de cerámica, de los cuales 30 corresponden a material diagnóstico entre bordes, golletes y fragmentos de cuerpo decorado. Por su decoración pueden dividirse en dos grupos: corrugado e 
inciso (diseño geométrico y ranurado). El conjunto incluye además tres apéndices con motivos zoomorfos y un fragmento de base (Figura 6-7a).
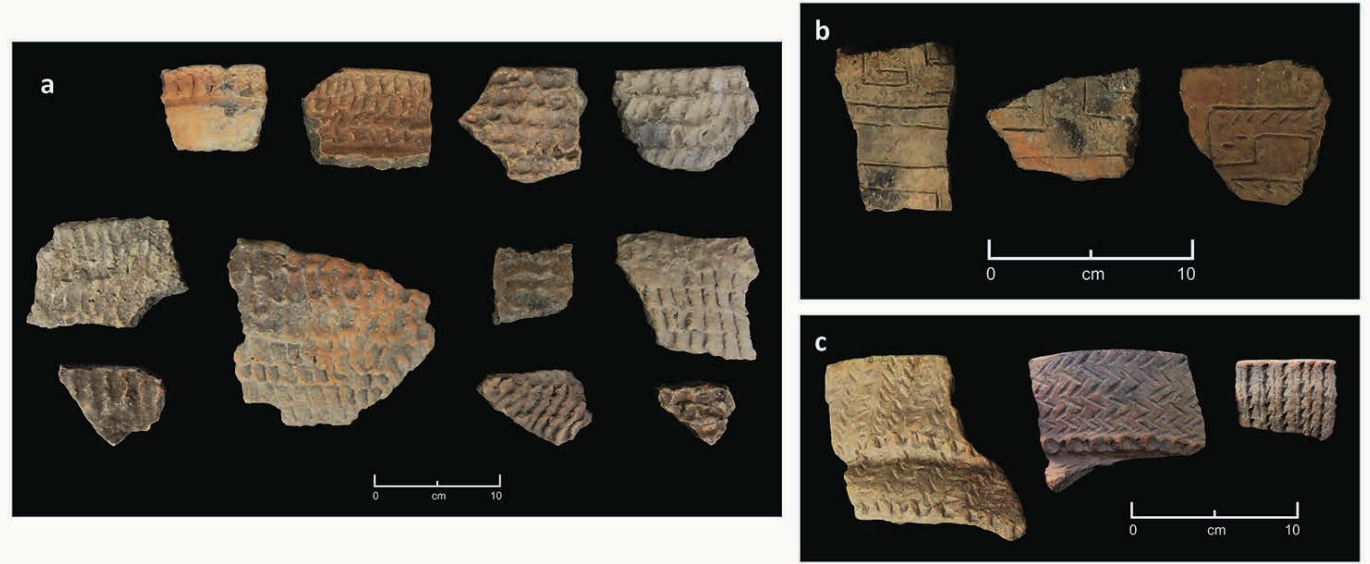

Figura 6. Fragmentos de cerámica diagnostica: (a) corrugado, (b) diseño inciso y (c) ranurado.
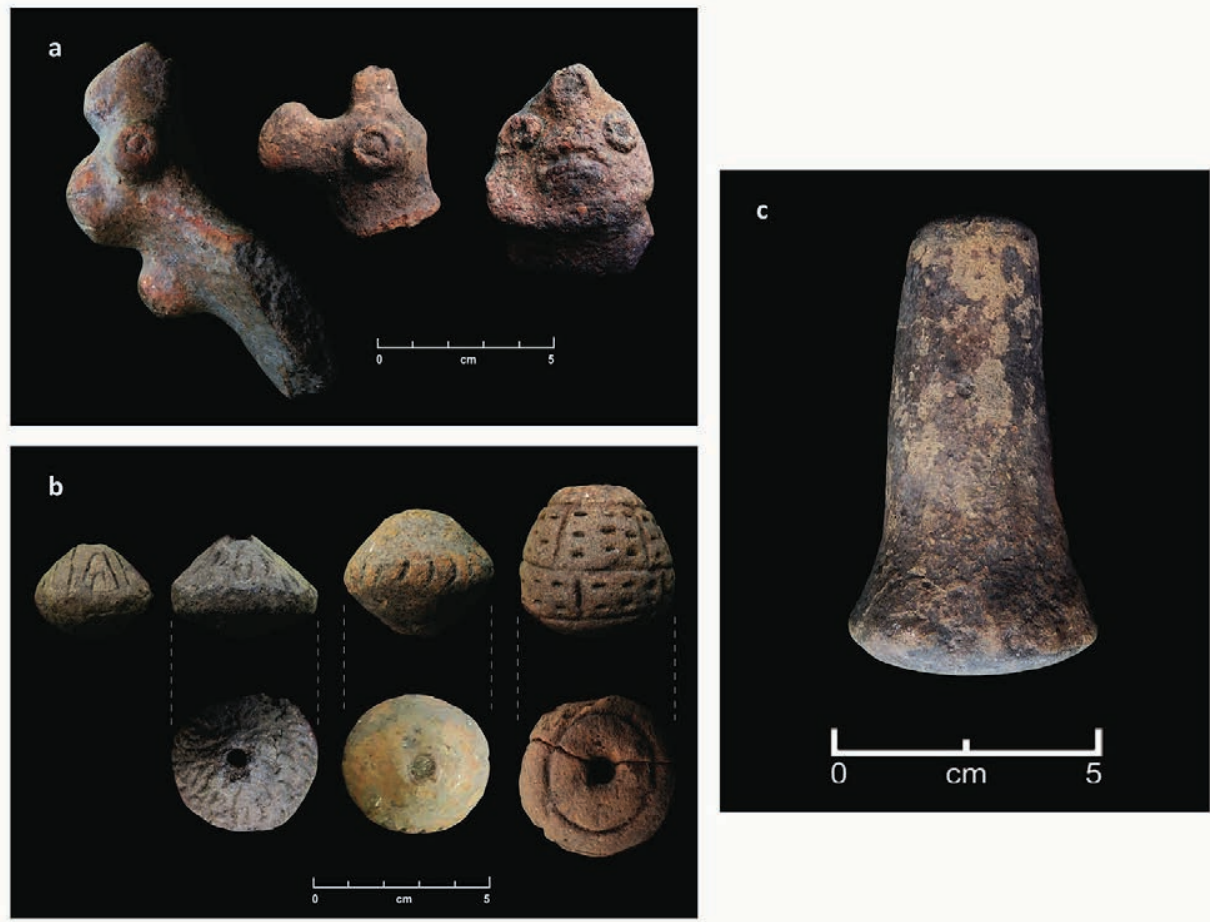

Figura 7. (a) Apéndices con motivos zoomorfos, (b) torteros con decoración incisa y (c) mano de moler.

La técnica de manufactura observada es el enrollamiento espiralado y la consistencia de la pasta es semicompacta (fractura irregular), teniendo como temperantes cerámica molida y en algunos casos ceniza. La pasta de los fragmentos varía en tonalidades que van del anaranjado al anaranjado marrón, con núcleo central gris, encontrándose la superficie interna de los fragmentos alisada.

Vasijas completas y fragmentadas: Se registraron dos vasijas completas y una fragmentada cuyas características son similares a las descritas para los fragmentos de cerámica, teniendo para los siguientes casos el tratamiento de la superficie interna y externa mediante el alisado (Figura $8)$. 

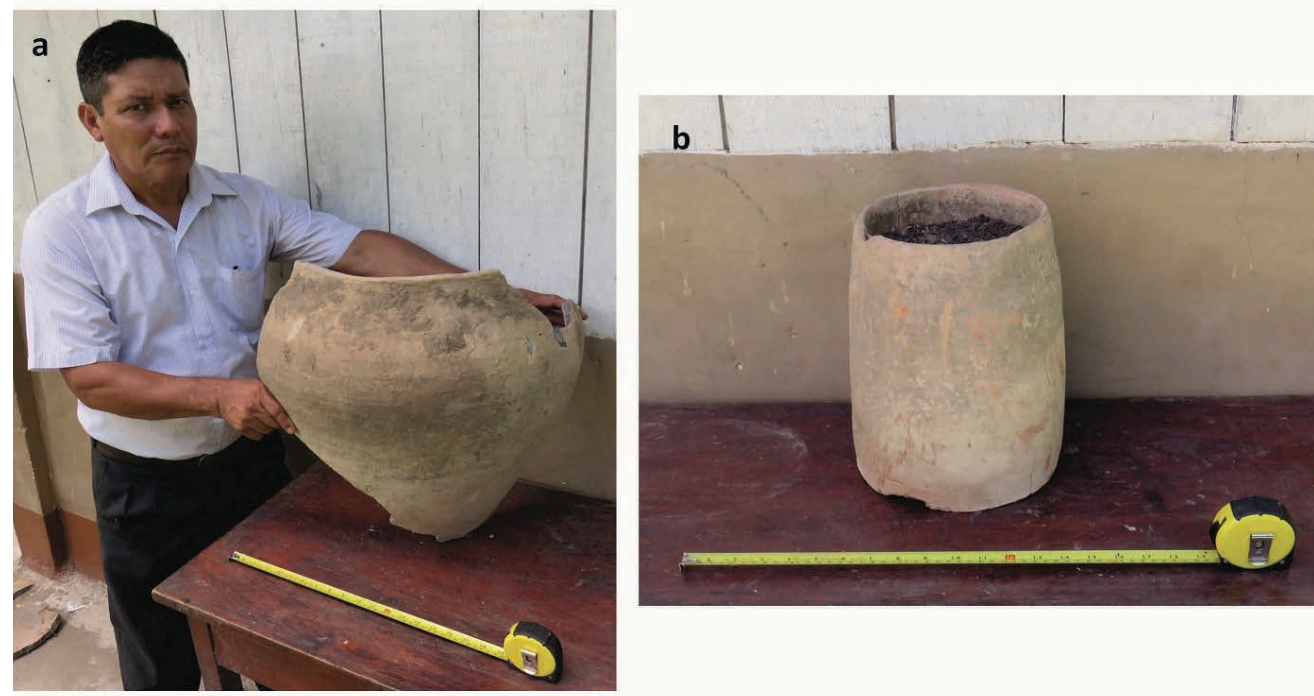

Figura 8. Urnas funerarias: (a) Espécimen 01 y (b) Espécimen 02 (El flexómetro indica 50 cm).

Espécimen 01, vasija cerrada de pared esférica y borde directo con labio plano. Espécimen incompleto. El perfil del fragmento permite señalar que se trata de una vasija de cuerpo ovoide en posición invertida, la sección conservada corresponde al $60 \%$ de la vasija y presenta una altura aproximada de $42 \mathrm{~cm}$.

Espécimen 02, vasija cerrada de cuerpo cilíndrico y base plana, presenta una ligera constricción a la altura de la boca, borde directo adelgazado con labio plano. Dimensiones: Altura $28 \mathrm{~cm}$ y diámetro de boca $20 \mathrm{~cm}$. Espécimen completo, muestra una fisura lateral y presenta despostillado en labio y base.

Espécimen 03, vasija cerrada de cuerpo esférico, gollete evertido, borde expandido y labio redondeado; presenta base plana. Dimensiones: Altura $19 \mathrm{~cm}$, diámetro de boca $10.5 \mathrm{~cm} \mathrm{y}$ diámetro máximo del cuerpo $20 \mathrm{~cm}$. Espécimen completo con desportilladuras en labio.

Instrumentos para hilar: Se contabilizó un total de 26 torteros; piezas especialmente elaboradas de diverso tamaño, forma y peso, ocho de los cuales presentaron decoración incisa (Figura 7b).

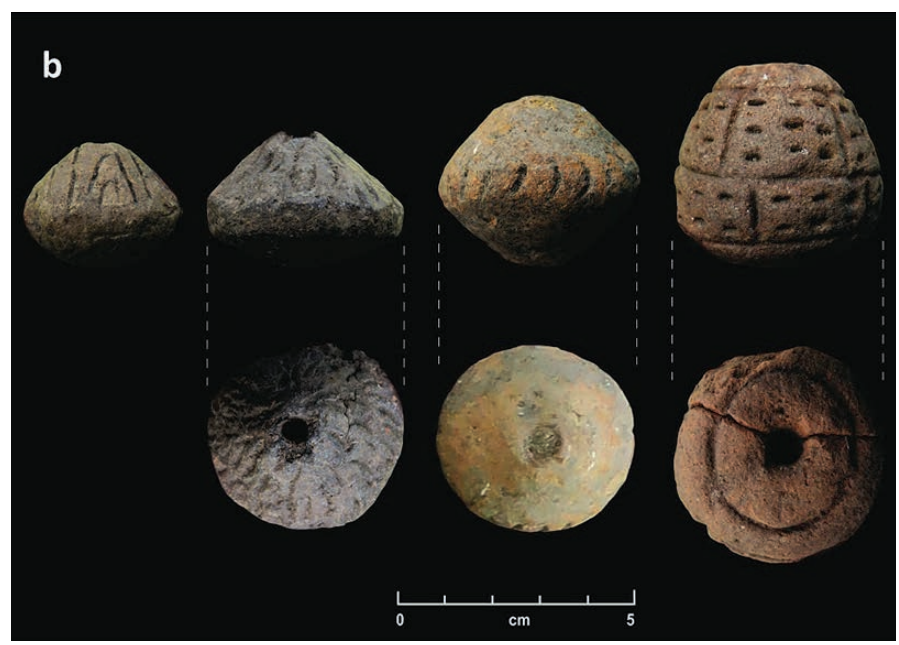

Figura $7 b$. Torteros con decoración incisa. 


\section{b) Lítico}

Hachas pulimentadas: Se observaron cuatro artefactos manufacturados mediante pulimento, instrumentos de corte por percusión directa, usados necesariamente enmangados. Uno de estos se encuentra fracturado, no conservando la parte distal y dos artefactos de la muestra se encuentran en la fase inicial de elaboración (Figura 9).

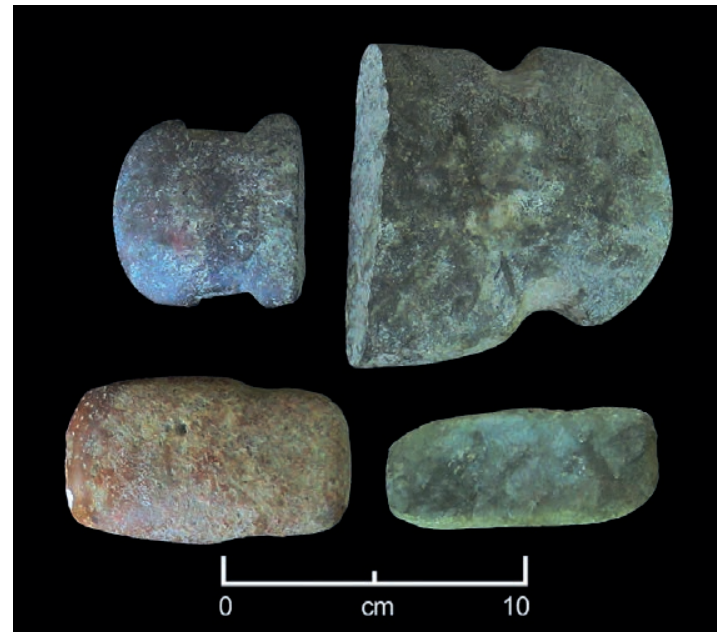

Figura 9. Hachas pulimentadas y preformas.

\section{Consideraciones finales}

Germán Shapiama Peñaherrera, antiguo poblador del lugar y actualmente Director de la IEP $\mathrm{N}^{\circ}$ 64204 San Salvador señala que los especímenes 01 y 02 de la muestra cerámica corresponden a urnas funerarias. Estos especímenes tendrían sus equivalentes en los contextos arqueológicos registrados por Blissenbach (1992) y Myers (1967) respectivamente.

Lathrap (1965) al registrar el sitio arqueológico UCA 24 reporta el hallazgo de urnas funerarias cilíndricas decoradas con diseños geométricos pintados, las cuales presentan un plato a manera de tapa y contenían restos óseos calcinados. El sitio arqueológico en mención se halla próximo a la comunidad nativa Santa Rosa, entre la desembocadura del río Pachitea y el río Tamaya, margen derecha del río Ucayali.

Los entierros en urnas funerarias habrían sido recurrentes en diversas zonas del Ucayali Central, en los sitios arqueológicos de Cumancaya (UCA 22) (Fung, 1981), Santa Rosa (UCA 24) (Lathrap, 1965); y el bajo Ucayali, en los alrededores de Contamana (Blissenbach, 1992), laguna Piracocha - José Olaya (UCA 28, UCA 30) (Myers, 1967), Cruz Molluna (Walsh Perú S.A., 2010, pp. 4.4-1-4.4-16), San José de Samiria en el medio Samiria (Morales, 2002, 2008) y en San José de Saramuro en el río Marañón (ECSA Ingenieros S.A., 2008, pp. 318-331).

En cuanto a los restos óseos, estos corresponden a inhumaciones dobles en urnas funerarias colocadas en cementerios comunitarios, dispuestos formando alineaciones o grupos, lo que en el último caso evidenciaría parentesco (Chaumeil, 1997).

La mayoría de materiales arqueológicos de la IEP N ${ }^{\circ} 64204$ San Salvador provienen de entierros removidos. Entre estos materiales destaca una gran cantidad de torteros los cuales, junto al huso, constituyen un instrumento para hilar, siendo este un indicador de la actividad textil en el área. Morales $(2002,2008)$ y Ruiz $(2005,2006,2008)$ registran torteros en el sitio arqueológico El Zapotal como artefactos asociados a los entierros de urnas funerarias. 
Con base en la evidencia arqueológica documentada e información oral brindada por los pobladores acerca de los hallazgos fortuitos, puede establecerse que el sitio arqueológico San Salvador corresponde a un asentamiento de carácter habitacional, el cual incorpora un cementerio de entierros secundarios en urnas cerámicas funerarias. Los materiales arqueológicos observados en San Salvador corresponden al complejo arqueológico Cumancaya, situado temporalmente entre los siglos IX y XIV de la era común (Guffroy, 2006; Fung, 1981 y Rivas ed., 2010).

Cabe resaltar que dentro de la tradición oral del pueblo shipibo-conibo del Ucayali central, se reconoce a los parajes conocidos como la laguna Cumancaya y los cerros Canchahuaya, relacionados a antiguos lugares de ocupación indígena (Heath, 2002; Valera, 2005).

\section{Agradecimientos}

Al Lic. Santiago Rivas Panduro, Sub Director de la Dirección Desconcentrada de Cultura de Loreto del Ministerio de Cultura, por brindarme los materiales y los comentarios referentes a la inspección arqueológica realizada en el área del centro poblado rural San Salvador; al Sr. Germán Shapiama Peñaherrera, Director de la IEP N 64204 San Salvador por facilitarme la documentación y permitirme el acceso a la colección de materiales arqueológicos procedentes del sitio arqueológico San Salvador. Al Sr. Homero Morey Hidalgo, escritor e investigador local; al Sr. Humberto Zevallos Chávez, escritor y poeta; al Sr. Raúl Zevallos Ríos y Sara Ríos Vela, Director y Coordinadora de la Revista Carta Abierta, por las referencias a la arqueología del área de Contamana y sus inmediaciones.

\section{Bibliografía}

Agencia de Noticias de Contamana (2011). Sitio arqueológico Cachique es el nuevo descubrimiento realizado por el Ministerio de Cultura cerca a San Salvador en Contamana. Recuperado en 12 de Octubre de 2011 de http:// agenciadenoticiascontamana.com.pe/?p=171

Ahora (10 de marzo de 2011). Bachiller de la UNAP encuentra vasija histórica a una hora de la ciudad. Ahora, p. 6.

Blissenbach, E. (1992). Evidence for earlier settlements near Contamana; rio Ucayali; Upper Amazon. BaesslerArchiv 40(1): 17-25.

Bonavia, D. (1966). Sitios Arqueológicos del Perú (Primera Parte). Arqueológicas (9): 3-71.

Chaumeil, J. (1997). Entre la memoria y el olvido. Observaciones sobre los ritos funerarios en las tierras bajas de América del Sur. Boletín de Arqueología PUCP (1): 207-232.

ECSA Ingenieros S.A. (2008). Estudio de Impacto Ambiental del Proyecto de Prospección Sísmica 2D Lote 106 Cuenca Marañón. Lima: Manuscrito en archivo, Ministerio de Energía y Minas.

El Contamanino (2013). La campana de Sarayacu. El Contamanino, (32): 18.

Forero, J. (5 de setiembre de 2010). Scientists find evidence discrediting theory Amazon was virtually unlivable. The Washington Post. Recuperado en 6 de Setiembre de 2010 de http:/www.washingtonpost.com/wp-dyn/ content/story/2010/09/04/ST2010090400158.html?sid=ST2010090400158

Fung, R. (1981). Reseña de Cumancaya: A Peruvian Ceramic Tradition. Amazonía Peruana 4(8): 125-128.

Guffroy, J. (2006). El horizonte corrugado: correlaciones estilísticas y culturales. Bulletin de l'institut français d'études andines 35(3): 347-359.

Heath, C. (2002). Mitos y leyendas del grupo shipibo-conibo. En Alayza, P. y F. Torres (ed.). Una ventana hacia el infinito: Arte shipibo-conibo (pp. 25-28). Lima: Instituto Cultural Peruano Norteamericano.

Impetu (5 de noviembre de 2012). En caserío Betania descubren tinajas con restos óseos. Impetu, p. 4.

Instituto Nacional de Cultura (1993). Acta de verificación [de] restos arqueológicos en el centro poblado "San Salvador". Instituto Nacional de Cultura, Filial Departamental de Loreto, Sede Ucayali - Contamana. Contamana: Manuscrito en archivo, IEP Nº 64204 San Salvador. 
Lathrap, D. (1965). Investigaciones en la selva peruana, 1964/1965. Boletín del Museo Nacional de Antropología y Arqueología 1(4): 9-12.

Ministerio de Cultura (2011a). Acta de supervisión $N^{\circ}$ 004-2011/AA/MC-DRC-LOR/SRP. Ministerio de Cultura, Dirección Regional de Cultura Loreto. Iquitos: Manuscrito en archivo, Dirección Desconcentrada de Cultura de Loreto del Ministerio de Cultura.

Ministerio de Cultura (2011b). Informe $N^{\circ}$ 060-2011/AA/MC-DRC-LOR/SRP. Ministerio de Cultura, Dirección Regional de Cultura Loreto. Iquitos: Manuscrito en archivo, Dirección Desconcentrada de Cultura de Loreto del Ministerio de Cultura

Morales, D. (2000). Las poblaciones prehistóricas amazónicas. Investigaciones Sociales 4(6): 71-92.

Morales, D. (2002). Contactos entre cocamas y shipibos: Un acercamiento arqueológico en la amazonía peruana. Investigaciones Sociales 6(10): 47-70.

Morales, D. (2008). Reconstruyendo algunos aspectos socioculturales de artefactos excavados en Bajo UcayaliPerú. Amazonía Peruana 15(31): 211-249.

Myers, T. (1967). Reconocimiento arqueológico del Ucayali Central. Boletín del Museo Nacional de Antropología y Arqueología 1(6): 5-7.

Myers, T. (1990). Sarayacu: Ethnohistorical and Archaeological Investigations of a Nineteenth-century Franciscan Mission in the Peruvian Montaña. Lincoln: University of Nebraska Studies: New Series no: 68. University of Nebraska.

Panaifo, M. (1994). Evaluación de la arqueología amazónica peruana. En Amazonía, en busca de su palabra (pp. 167-229). Iquitos: Instituto de Investigaciones de la Amazonía Peruana.

Ravines, R. (ed.) (2011). San Salvador. Boletín de Lima, 34(163-166): ---376, 457.

Rivas, S. (2006). Proyecto Qhapaq Ñan: La arqueología de la región Loreto (selva baja de la amazonia peruana), estado de la cuestión. Informe Final. Iquitos: Manuscrito en archivo, Instituto Nacional de Cultura - Regional Loreto.

Rivas, S. (ed.) (2010). El Alto Amazonas. Lima: Chätäro.

Rojas, R. (comp.) (2011). Origen y fundación de Contamana. Crónicas y Relatos Ucayalinos. Pucallpa: Victoria.

Ruiz, E. (2005). Evidencias arqueológicas de contextos funerarios en el sitio de San José de Samiria, Loreto. Boletín de Estudios Amazónicos 1(1): 25-29.

Ruiz, E. (2006). Los Omagua: antiguos tejedores de la amazonía. Boletín de Estudios Amazónicos 1(2): 99-105.

Ruiz, E. (2008). Patrones funerarios en San José de Samiria, Loreto y sus variaciones a través del tiempo. Amazonía Peruana 15(31): 251-267.

Selva (1976). Gran descubrimiento de Daniel Donayre C. Selva, 2(10): 1, 6.

Selva (1981). La ciudad perdida de Cushabatay. Selva, 8(28): 11.

Shapiama, G. (2013). Reseña histórica: Datos históricos del caserío de San Salvador. Contamana: Manuscrito en Archivo, IEP N ${ }^{\circ} 64204$ San Salvador.

Valera, E. (2005). Cumancaya. En Landolt, G. (ed.). El ojo que cuenta, mitos y costumbres de la Amazonía indígena, ilustrados por su gente (pp. 25-29). Lima: Ikam.

Walsh Perú S.A. (2010). Estudio de Impacto Ambiental Prospección Sísmica 2D y Perforación Exploratoria - Lotes 134 y 158. Lima: Manuscrito en archivo, Ministerio de Energía y Minas.

Zevallos, H. (2001). Las misteriosas tumbas nativas de San Salvador. Contamana 1(1): 11-12.

Zevallos, R. (2015). Contamana, en la historia de la Amazonía. Lima: Grupo Metrópolis.

Presentado: 10 noviembre 2017

Aceptado: 2 febrero 2018

Publicado online: 27 febrero 2018 